\title{
REMOTE WORKING CONCERNS DURING THE COVID-19 PANDEMIC
}

\author{
Iza Gigauri \\ $\mathrm{PhD}$ in Business Administration, Associate Professor, School of Business, Computing and Social \\ Sciences, St. Andrews Georgian University, Tbilisi, Georgia \\ DOI: 10.46609/IJSSER.2020.v05i10.005 URL: https://doi.org/10.46609/IJSSER.2020.v05i10.005
}

\begin{abstract}
The new Corona virus Covid-19 pandemic has altered the way people are living and working. Human resource management playing a key role in digital transition encounters serious challenges with respect to employee wellbeing, and organizational changes. The paper addresses remote working before and during the pandemic. It examines HRM initiatives and projects focusing on employee wellbeing during the crisis, and outlines communication issues while teams work online. The paper also analyses the perception of flexible working and work-life balance. Primary empirical data was collected through a survey of Georgian HR managers. HRM should overcome remote working challenges with supporting activities, and help organizations to adapt to 'new normal' and to prepare for 'next normal'. The paper contributes to understanding issues concerning remote work, and offers suggestions for future studies.
\end{abstract}

Keywords: Digitalization, flextime schedule, work-life balance, wellbeing, lockdown, teleworking, Georgia

\section{Introduction}

The Covid-19 pandemic has had a huge impact on organizations of any size and type. As a response to the emerged crisis, enterprises had to shift to digital business processes. The importance of digitalization has extremely increased during the pandemic with respect to remote management and e-commerce. In many cases, companies responded positively to the crisis introducing or using e-commerce platforms.

Accelerated digitalization has posed problems in terms of employee adaptation to the new reality. Therefore, HRM plays an important role to support workers at such rough times full of uncertainties. Under the circumstances, organizations should adopt less strict and more adjustable policies to support flexible working, encourage frequent communication, modify performance management, and care for work-life balance. 


\section{International Journal of Social Science and Economic Research}

ISSN: $2455-8834$

Volume:05, Issue:10 "October 2020"

Thus, Covid-19 crisis created incentives for digitalization and more companies now perceive its benefits. However, it should not happen at the expense of employee wellbeing. Therefore, remote working management in conjunctions with employee physical and mental health is the strategic focus of HRM during the transitions due to the pandemic.

Although the links between remote working and employee experience of work-life balance have been devoted scholarly attention, the pandemic has highlighted these relations once again. However, relatively little appears to be written in this respect on Georgian context.

The study answers the following research questions: (1) Did organizations change the policy regarding remote working due to the pandemic lockdown? (2) How employees, teams, and HR managers worked remotely? (3) What has been the main focus of HRM concerning employee wellbeing while working remotely? (4) How HR managers perceived flexible working and worklife balance during the pandemic crisis?

The rest of the paper is organized as follows. First, the existing literature on remote working and work-life balance is reviewed. Second, research methodology and analysis approach for this study is outlined. Then, research results are presented followed by discussion and conclusion. Finally, research limitations are clarified and future research avenues are suggested.

\section{Literature Review}

The global outbreak of new coronavirus COVID-19 (NIH, 2020) caused socio-economic problems and affected human resources. International Labour Organization foresees the dramatic increase in unemployment (ILO, 2020).AS a result, the pandemic crisis can be defined as "Grand Challenge" that requires joint, coordinated and cooperative efforts around the world to overcome it (George, Howard-Grenville, Joshi \&Tihanyi, 2016; Ferraro, Etzion \&Gehman, 2015; Eisenhardt, Graebner\& Sonenshein, 2016).

The Covid-19has increased digital transformation resulting in demand in technological skills of employees (Sheppard, 2020) to work online, and hence,HRM should meetthe need to reskilling the workers(World Economic Forum, 2020).

Moreover, the pandemic has transformed not only the way businesses operate, but also the routine people work(Malecki, 2020). The largest remote workforce is formed due to the pandemic as people are working from home(Malecki, 2020) to hinder the virus from spreading and to protect employees' health. Consequently, technological shifts have been implied HRM to adapt to the global changes to remain efficient and innovative(Mushkudiani et al., 2020). 


\section{International Journal of Social Science and Economic Research}

ISSN: $2455-8834$

Volume:05, Issue:10 "October 2020"

Telecommuting and flexible working schedule leads to productive businessfor the benefit of both employers and employees (Dowling, 2012), but this should not be achieved at the expense of employees' health. Work-life balance related to remote work establishes opportunities and challenges (Soroui, 2020). For example, talent acquisition during the lockdown took place with online recruiting procedures at many organizations worldwide.

In general, crisis negatively influences employees' health, and tackling a crisis can cause burnout (Maslach \& Leiter, 2008). Moreover, employees experience emotional issues due to shortage of informal contacts while working remotely (Smith, 2020). Therefore, HR managers should treat employees with compassion and allow more flexibility (Howlett, 2020). Previous research asserted that workplaces with flexible design have led to positive results(Subramaniam et al., 2013). In addition, continuous communication with employees regarding current developmentsis helpful(Fallon, 2020), as well as getting feedback from the staff to ensure their safety and productivity (Parsi, 2016).However, face-to-face relations still is more important for employees than online interaction while teleworking (Coenen \& Kok, 2014).

As working remotely is blurring boundaries between work and personal life, employee emotional state and experience should be addressed (Hancock \& Schaninger, 2020). In this regard, HR managers should devote a special attention to employee wellbeing during the crisis as economic and job uncertainties can lead to decreased physiological health (Godinic, Obrenovic, \& Khudaykulov, 2020). Moreover, HRM needs to focus on strategies concerning employee physical, emotional, and financial wellbeing to help organizations to survive (Walsh \& Resch, 2020).

Social interaction is critical during remote working. Isolation while telecommuting can result in less commitment because working relations provide socialization, participation, sense of belongings and trust (Godinic, Obrenovic, \& Khudaykulov, 2020). Therefore, small-group meetings or virtual connections can improve work relations and increase employee motivation (Singer-Velush, Sherman, \& Anderson, 2020).

Although Georgia has been less affected by the pandemic in terms of number of infected citizens and death cases (StopCov.ge, 2020), its negative effect on business is severe due to the strict regulations the government enacted with the purpose to avoid spreading the new coronavirus (Gov.ge, 2020). However, decreased demand, travel ban, stock shortages, problems with transportation and supply chain caused income reduction and hence, employee dismissals (Babych, Keshelava, \& Mzhavanadze, 2020; Gigauri, 2020). Many enterprises suspended business activities but others moved online (PwC Georgia, 2020). As a result of the pandemic, Georgian companies hitherto uninterested in digitalization and online trade, are forced to show 


\section{International Journal of Social Science and Economic Research}

ISSN: 2455-8834

Volume:05, Issue:10 "October 2020"

interest in E-commerce. Thus, they allow remote working to their employees and encourage HRM function to adjust the policies and strategies accordingly.

The previous studies emphasized the benefits of digital economy for Georgia und urged the creation of ecommerce, digital market, and digital business environment by adopting necessary political mechanisms (Abuladze \& Gigauri, 2017).

Although digitalization and e-commerce present assets in tackling the negative consequences of Covid-19, this is not yet a mainstream in Georgia. E-commerce has been less attractive especially among those Georgian companies engaging in the export. Nevertheless, the pandemic raised awareness of digitalization and demonstrated the necessity of organizations to think more about digital processes.

Thus, the current pandemic crisis triggers organizations of all type and size to adapt quickly to 'new normal' and prepare to 'next normal'in order to survive. The main tool to meet adequately the changes is viewed online working systems and hence, digitalization. In this respect, HRM has a leading role to manage necessary transitions and direct efforts to employee wellbeing taken into consideration the drawbacks in remote working.

\section{Methodology}

The study is based on quantitative research approach. Data was collected in June 2020 by selfadministered questionnaire, which has been sent through Email.

The respondents were selected from the closed HR groups in the Social Media (Facebook and LinkedIn) with the random sampling method. Overall, 150 managers were invited to participate in the survey. Actually, the HR managers from forty-eight organizations filled in the questionnaire totaling $32 \%$ response rate.

The surveyed managers represented companies the following sectors: Service industry such as healthcare, IT, telecommunication, insurance, consulting, media, tourism, and hospitality; Manufacturing, production, and construction; Bank and financial sector; Transportation, logistics, distribution, and E-commerce.

The questionnaires included close-ended questions, but also open-ended question. Closed ended questions contained dichotomous(binary - yes/no) items, multiple choice and multiple response questions, and 5-pointLikert scale items where 1=strongly disagree, 2=disagree, $3=$ neither disagree nor agree, $4=$ agree, $5=$ strongly agree. 
The gathered data was analyzed with SPSS by descriptive statistics. Additionally, reliability statistics was also conducted. Cronbach's alpha for all corresponding items is above 0.5 to 0.9 indicating the acceptable reliability of the questionnaire.

\section{Research Results}

In total, managers from forty-eight organizations took part in the survey $(\mathrm{N}=48) .46$ percent of the surveyed companies are large $(n=22)$, and 54 percent are small- $(n=12)$, and medium-sized $(n=14)$ (Figure 1). According to the classification of National Statistics Office of Georgia (Geostat, 2020), large companies are those, where average annual number of employed exceeds 250 persons; the average annual number of employed in medium-sized enterprises ranges between 50 and 250 persons, and small companies have less than 50 employees.

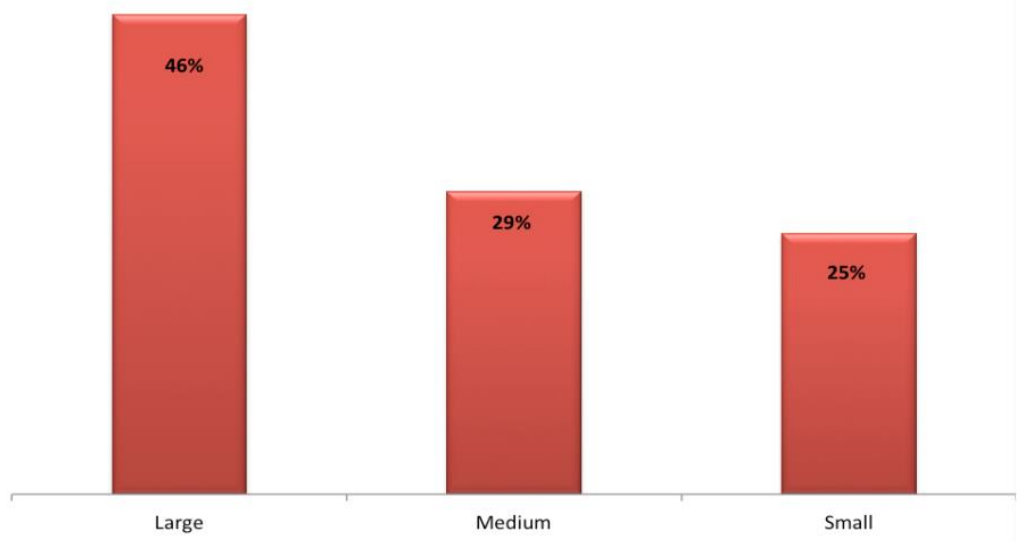

Figure 1. Surveyed organizations by size

The majority of managers participating in the survey are Heads of human resource department, 10 of them work as company directors and 6 participants are other leaders performing human resource functions.

The majority of the managers participating in the survey (23) have worked on their current leading positions up to 5 years, and 17 of them from 5 to 10 years, whereas only one respondent has worked on that position more than 15 years (Figure 2). 


\section{International Journal of Social Science and Economic Research}

ISSN: 2455-8834

Volume:05, Issue:10 "October 2020"

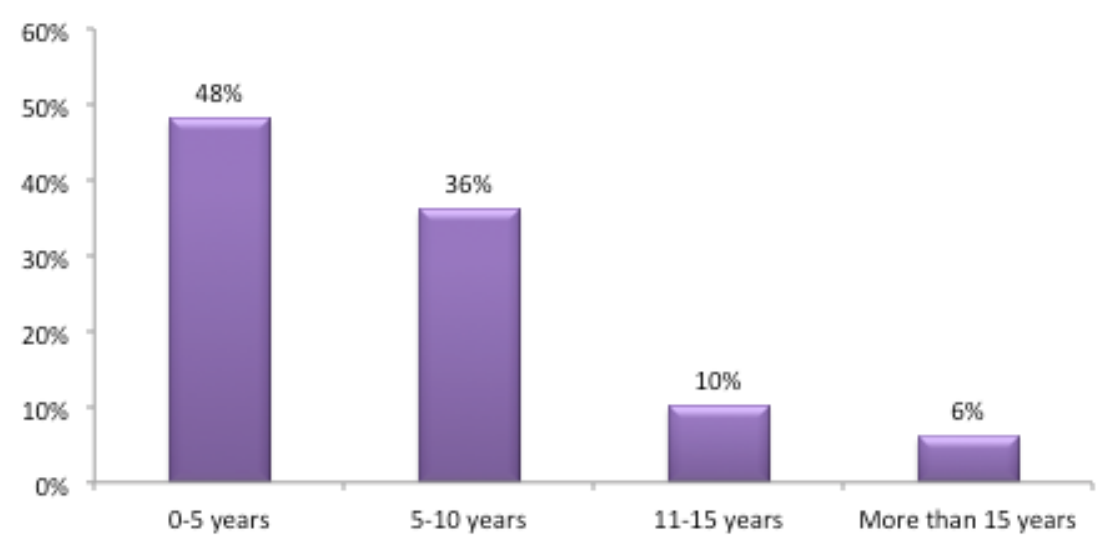

Figure 2. Respondents working years at their current job

The pandemic has enforced alteration in the working routine at all enterprises. The most of the companies have organized the work in such a way to avoid density at the workplace. Besides, they introduced shifts, switched completely to the remote working, or changed working hours. 25 percent of the respondents stated that their employees entirely work remotely during the pandemic, but 40 percent reported that they changed the approach involving spreading out the density of employees throughout a workday. More small companies went completely remotely during the pandemic while large companies arrange the workplace in a fashion to decrease concentration of people (Figure 3).

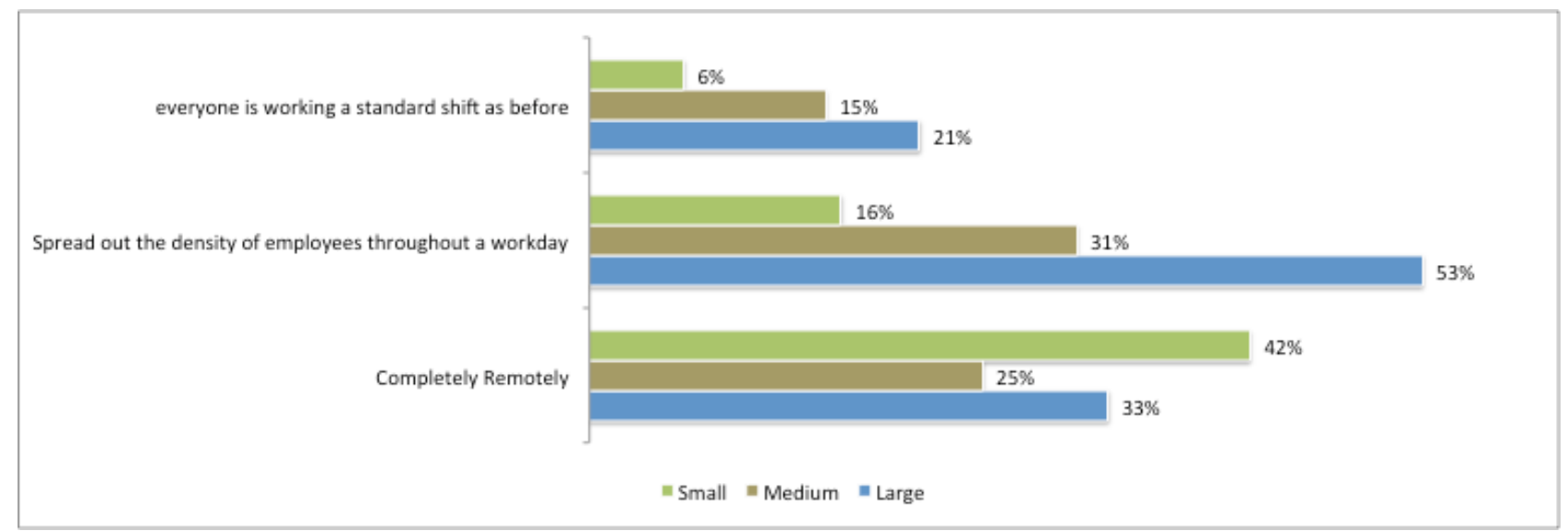

Figure 3. How have employees worked since the Covid-19?

Accordingly, the pandemic changed how team working was performed. The teams have mostly worked through the Internet meetings using online conferencing tools in the course of the lockdown (Figure 4). 


\section{International Journal of Social Science and Economic Research}

ISSN: 2455-8834

Volume:05, Issue:10 "October 2020"

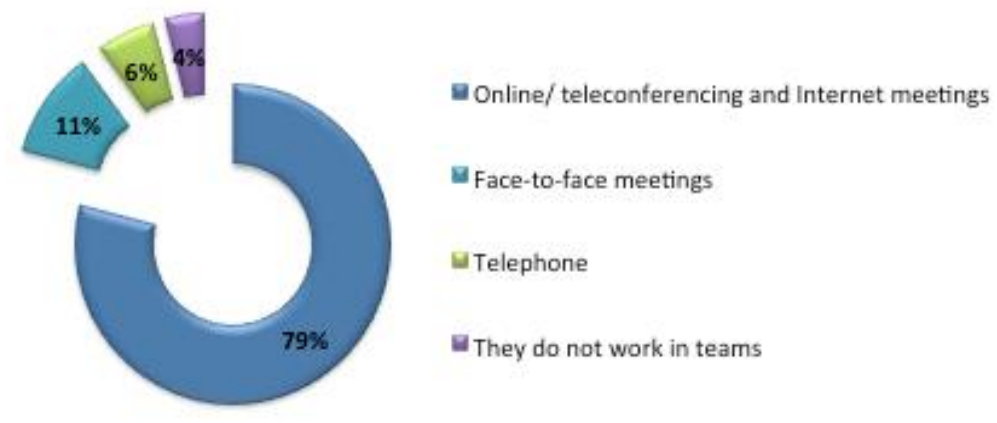

Figure 4. How have teams worked since the new coronavirus?

In the large companies, team working was conducted through the teleconferencing and online meetings. In the small companies, on the contrary, they either worked face-to-face or cancelled team meetings. Whereas, all companies were using phone working in teams (Figure 5).

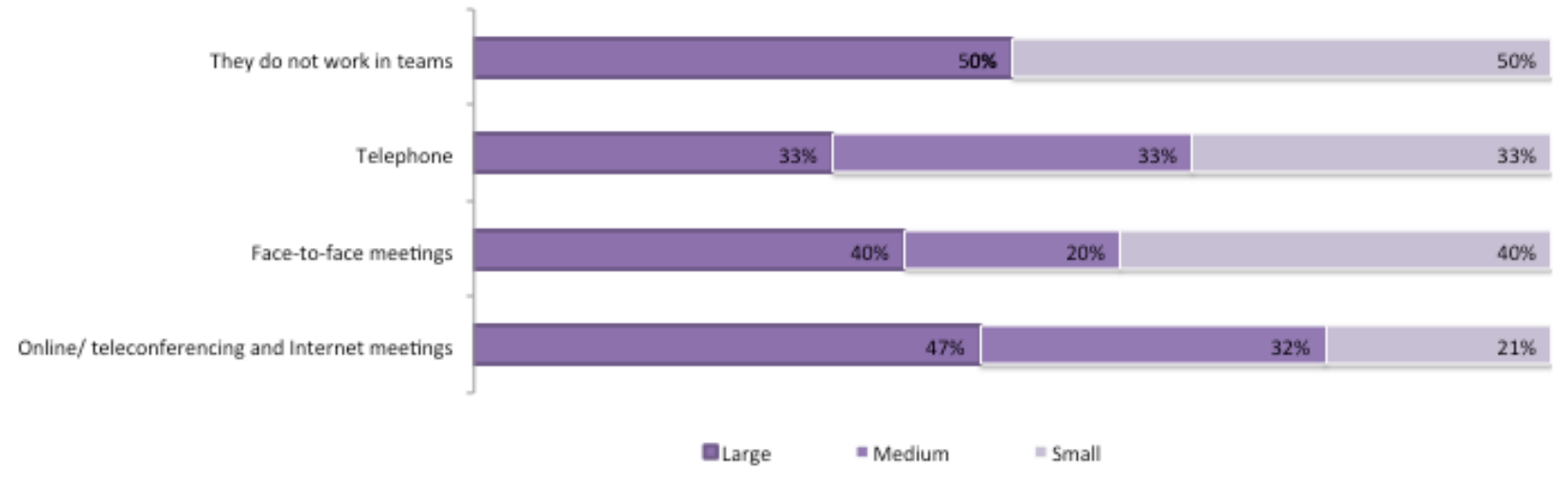

Figure 5. Team Working in Large organizations and SMEs

As expected, the majority of the organization $(81 \%)$ changed the policy regarding remote working because of the Covid-19 pandemic situation; compared with 19 percent i.e. 9 organizations that have not changed the organizational policy concerning distance working (Figure 6). 

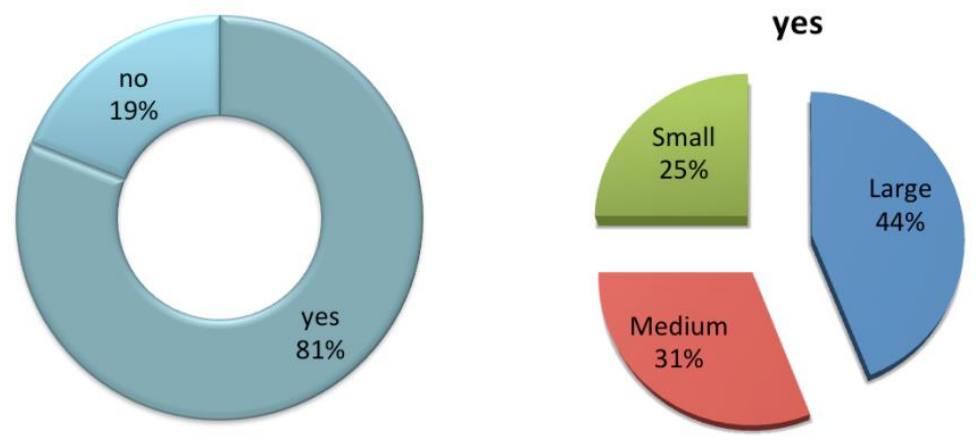

Figure 6. Did your organization change the policy regarding remote working because of the Covid-19 pandemic?

In should be noted that the respondents think that their organizations might retain remote working for eligible positions in future (Figure 7).

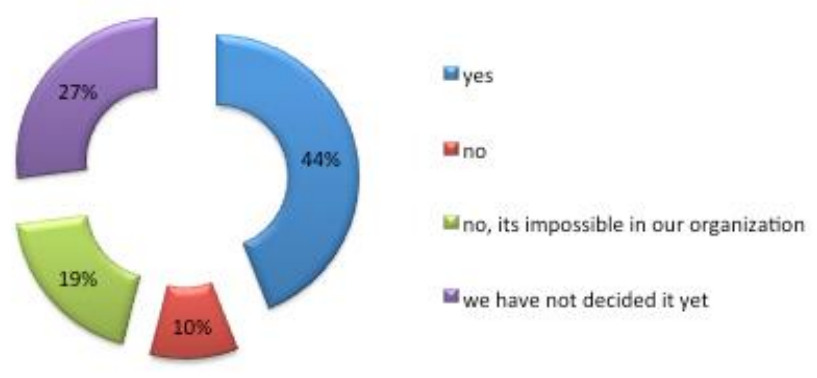

Figure 7. Continue Working Remotely

The managers have at least partly performed their work remotely since the Covid-19, which was a new experience for them,as they did not work remotely prior the pandemic(Figure 8).

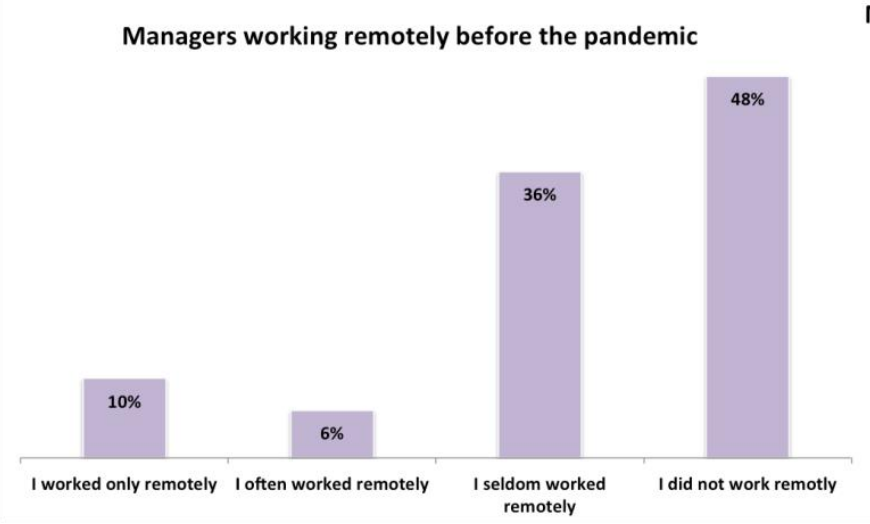

Managers working remotely after the pandemic

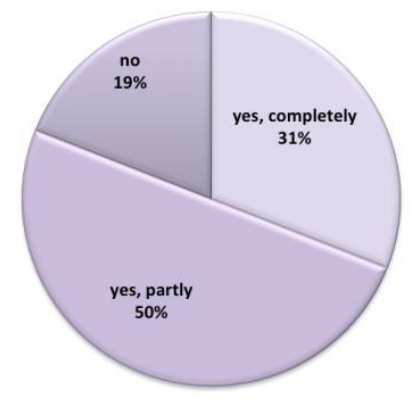

Figure 8 . Respondents personally performed their jobs remotely before and after the pandemic 
The crosstab between managers' working years on the leading positions of human resource management and whether they perform their jobs remotely since the pandemic have shown that 60 percent of HR managers with 0-5 years of experience and 13 percent of 11-15 years of experience in HRM have worked completely online (Figure 9).

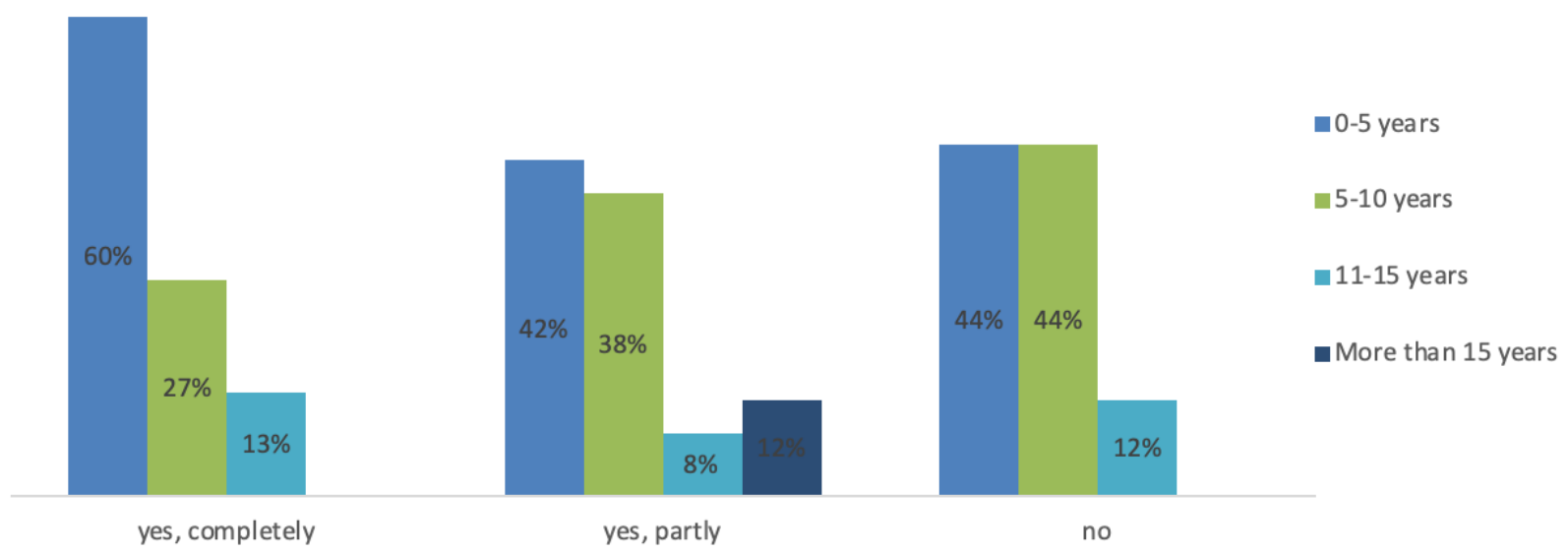

Figure 9. Have you personally performed your work remotely since the pandemic?

Since the employees have been working remotely from home in the period of pandemic, the work-life balance issues were critical tasks for managers to address. The surveyed managers agree or strongly agree that they have enough flexible schedule from work to meet their other responsibilities at home such as childcare (Figure 10). On the other hand, they agree or strongly agree that they have enough time to perform their tasks and duties at work. Nevertheless, they disagree or strongly disagree to the statement that they experience work-life balance.

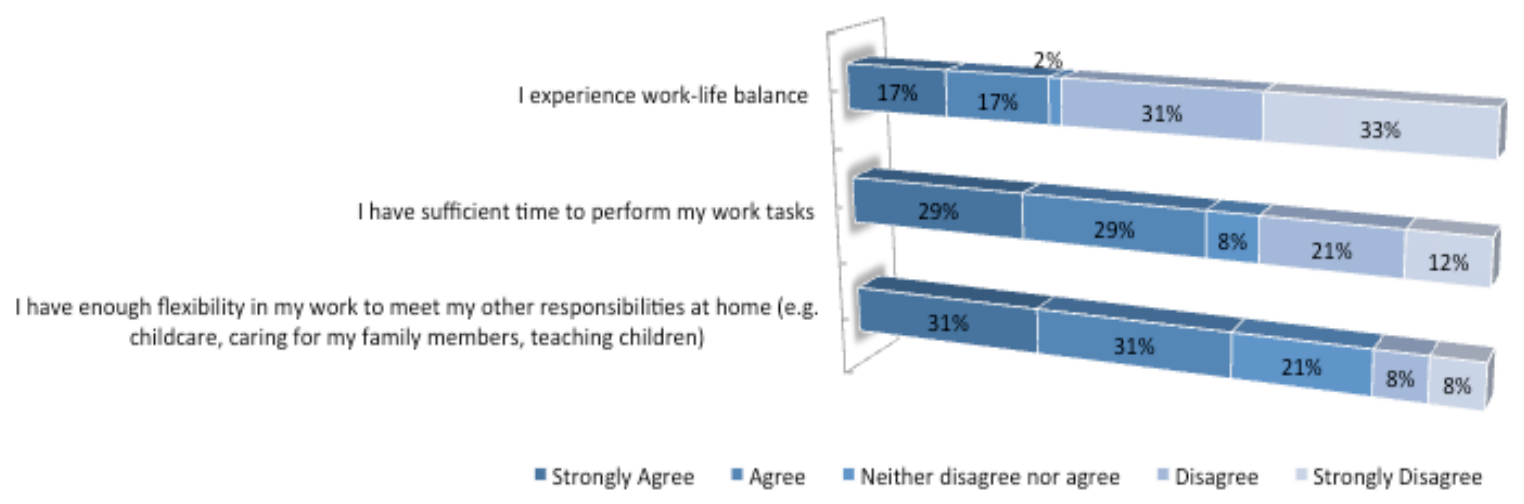

Figure 10. Respondents' Perception of Flexible Working and Work-Life Balance 
One of the most important issues to focus on during the remote work is the performance management. The managers participated in the survey had to respond to the open-ended question:"How have you ensured performance management taking into consideration the distance working routine?". As a result, they offered wide range of solutions. The responses have been analyzed with content analysis approach, which have revealed that managers trusted to the employees and did not control their job activities with micromanagement. However, they have openly and constantly communicated with the staff helping them to adapt to the remote working system as well as to encourage, motivate, and praise them. Companies enabled all technological tools to help them perform their jobs. Besides, guidelines were created for managers to help them to monitor the employees remotely and enable team-working activities online. Managers took care of emotional state of employees, and were engaged in managing stress and changes. The employees performed their tasks with responsibilities and did not require directives from the management or close monitoring. In addition, employees were aware of their important role in the survival of the company, consequently they were doing their jobs with responsibility and discipline.

Some respondents reported that they were using a specific online working system to collect statistical data about working hours and performed tasks. The reporting system was also applied by which all employees wrote reports about the tasks and duties they have performed.

In general, the HR managers filled in the questionnaire expressed their satisfaction with the performance of their employees while working remotely during the pandemic.

In order to maintain regular communication with the staff, organizations used online communication tools such as Zoom, Skype, Meet, Teams, as well as Phone and Email simultaneously (Figure 11).

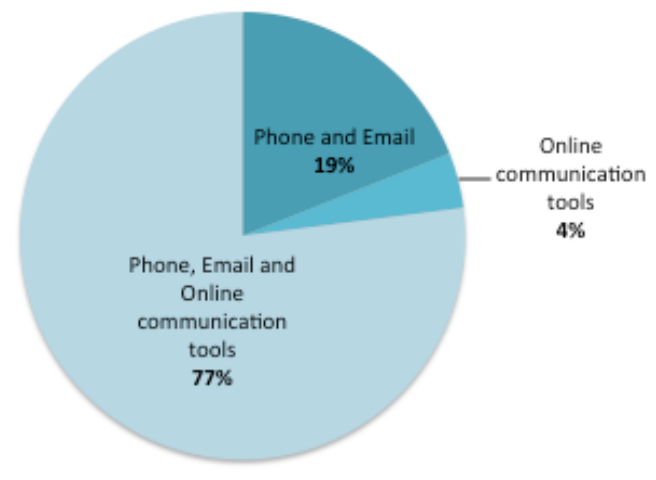

Figure 11. Communication tools used during the pandemic 
International Journal of Social Science and Economic Research

ISSN: 2455-8834

Volume:05, Issue:10 "October 2020"

As regards employee wellbeing, the managers have studied feelings and needs of the employees. For this reason, they have initiated projects to improve home office spaces and to improve their working environment. Besides, the employees were involved in projects, and their views were taken into consideration. The respondents indicated a high level of agreement with the statements that they help managers to improve relations with employees, commenced various projects to help employees and managers to adapt to the remote working conditions, and created agreeable atmosphere with the focus on organizational values and culture (Figure 12).

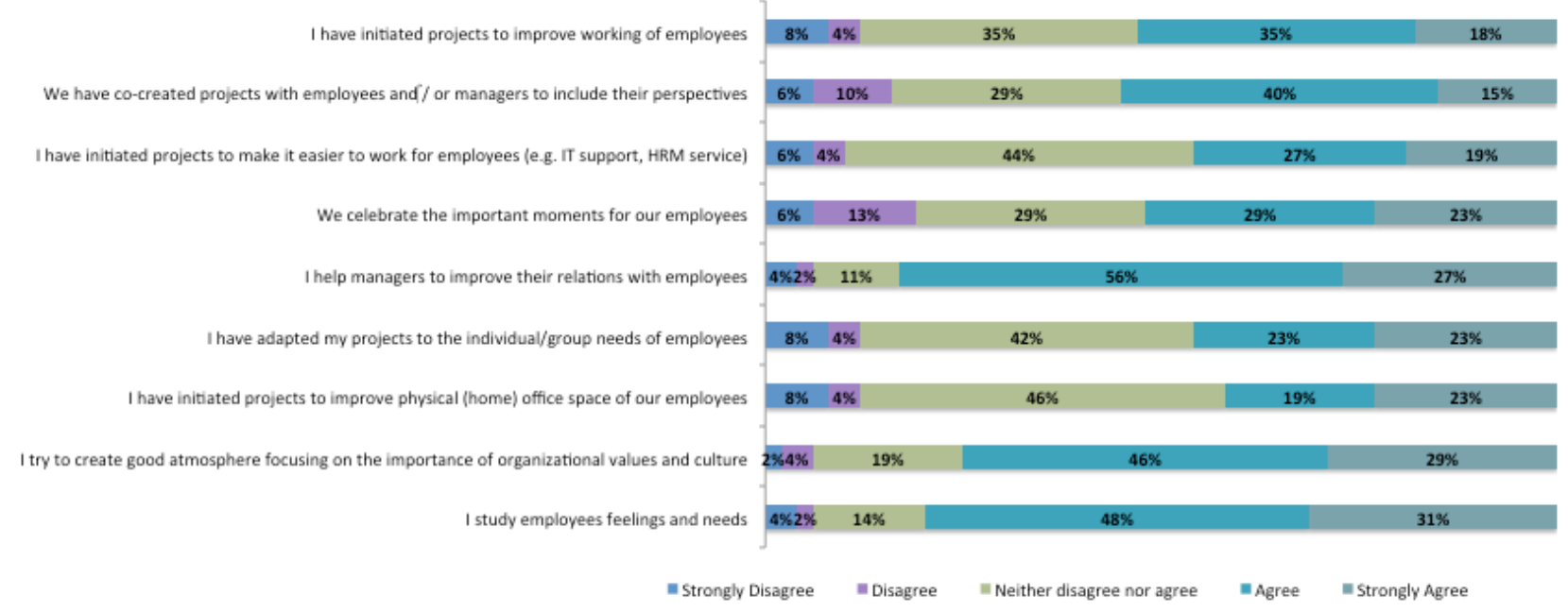

Figure 12. HRM Concern for Employee Wellbeing during the Pandemic

For this item, Cronbach's Alpha confirms the high internal consistency of the questionnaire $\alpha=0.91$ (Table 2).

Table 1. Reliability Statistics for Managers' Perception Regarding HRM Focusing on Employee Wellbeing

\begin{tabular}{|l|l|l|}
\hline Cronbach's Alpha & Cronbach's Alpha Based on Standardized Items & N of Items \\
\hline 0.909 & 0.911 & 9 \\
\hline
\end{tabular}

Thus, the research findings have shown that HR managers supportinginitiatives while working remotely is of significant importance, and HRM strategies should be tailored to meet the physical and mental health needs of employees.

\section{Discussion and Conclusions}

The presented research has outlined the challenges HRM faced during the pandemic in terms of remote working. The companies respond to the Covid-19 lockdown with Ecommerce platforms 


\section{International Journal of Social Science and Economic Research}

ISSN: $2455-8834$

Volume:05, Issue:10 "October 2020"

and moved businesses online. Digitalization is considered as a resilient tool for conducting business in the crisis. In should be also noted that upon reopening businesses, many Georgian companies returned to the pre-crisis habits and traditional way of conducting business, i.e. offline trade. The findings have indicated that even more companies to-date intend to switch remote working and move business processes online. This leads to digital management of employees causing disruptions at their works and lifestyles.

This research has focused on factors affecting employee wellbeing while working remotely. The research results have demonstrated that though the managers argued to have sufficient time to perform their tasks remotely and to have enough flexibility to meet their home responsibilities, they still experienced lack of work-life balance. Thus, more research will ascertain the perceptions of work-life balance and the need of managers as well as employees for achieve balancing work and home.

In this regards, physical and mental wellbeing are the key issues that have to be considered in the HRM policies and strategies. The research confirmed that HRM has focused on employee welfare by initiated various projects to improve relations, work conditions and climate placing emphasis on organizational culture and values.

Even though the pandemic is a negative career shock, it may have longer-term positive implications for some individuals. Further studies will show the work and career implications of Covid-19 as a career shock, as well as to support people in dealing with this shock.

The new reality affected also team working, as they were not allowed to meet face-to-face but rather conduct online conferences, using digital communication tools and interact with phone. Yet the research has not clarified the satisfaction of employees with the communication tools and interaction with managers. Thus, more research needs to be performed to investigate this question from the viewpoint of employees.

The Georgian organizations had to alter the policy regarding remote working since the majority of them did not allow working from home prior the pandemic. For this reason, they have no experience in managing online. It has been established that managers have been working partly from home since the pandemic in comparison with other employees performing their jobs remotely. However, after the pandemic the organizations consider to continue enabling remote working for eligible positions and further develop the digital management systems.

With respect to performance management, remote working requires more trust and less micromanagement. Although HRM can use online monitoring and reporting systems, constant communication is of equal importance. Communication tools used during the pandemic included Zoom, Skype, Microsoft Teams, Google Meet, together with phone and email. This rapid shift to digital interaction required skills and understanding in new technologies. Consequently, formal 
International Journal of Social Science and Economic Research

ISSN: 2455-8834

Volume:05, Issue:10 "October 2020"

and informal training sessions should be conducted to raise employee confidence, motivation and knowledge.

Thus, HRM plays a pivotal role in combating the crisis by serving as a bridge between employees and top-management. It contributes to rapid adaptation of organizations to 'new normal' caused by Covid-19 pandemic.

\subsection{Study Limitations and Future Research Avenues}

This research applied cross-sectional data, but longitudinal data can givea complete picture of the implications of remote working on HRM system. The small sample size is another limitation, which was derived from the shortage of time, but probability sampling approach to collect data from larger sample will allow generalization of results.

The future research should identify key obstacles for companies in the way of transition to remote working as well as main opportunities of digitalization, costs and benefits, employee readiness to work with new technologies and the need to upgrade their professional and technological skills.

In terms of online team working, next research will establish the impact of this alteration on organizational performance.

More research will attempt to judge the attitude of HR managers towards work-life balance, namely: If they have enough time for doing their jobs properly and sufficient time to meet their responsibilities at home, what is the reason for their discontent with their work-life balance experience?

Future studies should also focus on the dynamic interaction between contextual and individual factors as the Covid-19 crisis may have differential implications for different people in different business sectors.

Finally, further research linking digitalization to HR outcomes could be of interest to policymakers, academics, and practitioners alike.

\section{References}

1. Abuladze, R., \& Gigauri, I. (2017). Ecosystem of Digital Economy in Georgia. SSRN Electronic Journal, http://dx.doi.org/10.2139/ssrn.2958038.

2. Babych, Y., Keshelava, D., \& Mzhavanadze, G. (2020). The Economic Response to COVID19: How is Georgia Handling the Challenge? Tbilisi: International School of Economics at TSU Policy Institute (ISET). 


\section{International Journal of Social Science and Economic Research}

ISSN: 2455-8834

Volume:05, Issue:10 "October 2020"

3. Coenen, M., \& Kok, R. A. (2014). Workplace flexibility and new product development performance: The role of telework and flexible work schedules. European Management Journal, 32(4), 564-576. https://doi.org/10.1016/j.emj.2013.12.003.

4. Dowling, M. (2012). Enabling remote working: protecting the network. Network Security, 3, 18-20. https://doi.org/10.1016/S1353-4858(12)70047-8.

5. Eisenhardt, K., Graebner, M., \& Sonenshein, S. (2016). Grand challenges and inductive methods: Rigor without rigor mortis. Academy of Management Journal, 59, 1113-1123. https://doi.org/10.5465/amj.2016.4004.

6. Ferraro, F., Etzion, D., \& Gehman, J. (2015). Tackling grand challenges pragmatically: Robust action revisited. Organization Studies, 36(3), 363-390. https://doi.org/10.1177/0170840614563742.

7. GCCI. (2020). COVID-19 Survey - Business Needs Assessment. Georgian Chamber of Commerce and Industry (GCCI.GE). Tbilisi: Georgian Chamber of Commerce and Industry.

8. George, G., Howard-Grenville, J., Joshi, A., \& Tihanyi, L. (2016). Understanding and tackling societal grand challenges through management research. Academy of Management Journal, 59(6), 1880-1895. https://doi.org/10.5465/amj.2016.4007.

9. Geostat. (2020). https://www.geostat.ge/en. Retrieved from National Statistics Office of Georgia.

10. Gigauri, I. (2020). Influence of Covid-19 crisis on Human Resource Management and Companies' Response: The Expert Study. International Journal of Management Science and Business Administration, 6(6), 15-24.

11. Godinic, D., Obrenovic, B., \& Khudaykulov, A. (2020). Effects of Economic Uncertainty on Mental Health in the COVID-19 Pandemic Context: Social Identity Disturbance, Job Uncertainty and Psychological Well-Being Model. International Journal of Innovation and Economic Development, 6(1), 61-74. http://dx.doi.org/10.18775/ijied.1849-75517020.2015.61.2005 .

12. Gov.ge. (2020). Government of Georgia. Retrieved September 2020, from http://gov.ge/index.php?sec_id=1\&lang_id=ENG

13. Hancock, B., \& Schaninger, B. (2020, July 27). HR says talent is crucial for performance and the pandemic proves it. Retrieved September 2020, from McKensey \& Company: https://www.mckinsey.com/business-functions/organization/our-insights/hr-says-talent-iscrucial-for-performance-and-the-pandemic-proves-it 


\section{International Journal of Social Science and Economic Research}

ISSN: $2455-8834$

Volume:05, Issue:10 "October 2020"

14. Howlett, E. (2020, June 10). How should HR support managers on staff wellbeing as the Covid crisis continues? Retrieved September 2020, from People Management:

https://www.peoplemanagement.co.uk/news/articles/how-should-hr-support-managers-onstaff-wellbeing-as-the-covid-crisis-continues

15. ILO. (2020). Global Impact and Policy Recommendations. Retrieved from International Labour Organization: https://www.ilo.org/global/topics/coronavirus/impacts-andresponses/lang--en/index.htm

16. Malecki, F. (2020). Overcoming the security risks of remote working. Computer Fraud \& Security, 7, 10-12. https://doi.org/10.1016/S1361-3723(20)30074-9.

17. Maslach, C., \& Leiter, M. P. (2008). Early predictors of job burnout and engagement. Journal of Applied Psychology, 93(3), 498-512. https://doi.org/10.1037/0021-9010.93.3.498.

18. Mushkudiani, Z., Gechbaia, B., Gigauri, I., \& Gulua, E. (2020). Global, economic and technological trends in human resource management development. Access Journal, 1(1), 5360. https://doi.org/10.46656/access.2020.1.1(4).

19. NIH. (2020). Coronavirus (COVID-19). Retrieved from National Institutes of Health: https://www.nih.gov/coronavirus

20. Parsi, N. (2016, October 25). Communicating with Employees During a Crisis. Retrieved September 2020, from SHRM: https://www.shrm.org/hr-today/news/hrmagazine/1116/pages/communicating-with-employees-during-a-crisis.aspx

21. PwC Georgia. (2020). Georgian Business in the face of the Covid-19 Pandemic. Tbilisi: $\mathrm{PwC}$ in Cooperation with Investors Council.

22. Sheppard, B. (2020, May 18). A guide to thriving in the post-COVID-19 workplace. Retrieved July 30, 2020, from World Economic Forum: https://www.weforum.org/agenda/2020/05/workers-thrive-covid-19-skills/

23. Singer-Velush, N., Sherman, K., \& Anderson, E. (2020, July 15). Microsoft Analyzed Data On Its Newly Remote Workforce. Retrieved September 2020, from Harvard Business Review: https://hbr.org/2020/07/microsoft-analyzed-data-on-its-newly-remote-workforce

24. Smith, R. (2020, May 1). How CEOs Can Support Employee Mental Health in a Crisis. Retrieved September 2020, from Harvard Business Review: https://hbr.org/2020/05/howceos-can-support-employee-mental-health-in-a-crisis

25. Soroui, S. T. (2020). Understanding the drivers and implications of remote work from the local perspective: An exploratory study into the dis/reembedding dynamics. Technology in Society, 101328, pre-proof. https://doi.org/10.1016/j.techsoc.2020.101328 . 
26. Spence, P. (2020, July 26). How COVID-19 reshapes the mental health needs of workers. Retrieved September 2020, from Ernst \& Young: https://www.ey.com/en_gl/health/howcovid-19-reshapes-the-mental-health-needs-of-workers

27. StopCov.ge. (2020). Prevention of Coronavirus Spread in Georgia. Retrieved from StopCov.ge: https://stopcov.ge/en

28. Subramaniam, G., Peck-Leong Tan, P. L., Maniam, B., \& Ali, E. (2013). Workplace Flexibility, Empowerment and Quality of Life. Procedia-Social and Behavioral Sciences, 105, 885-893. https://doi.org/10.1016/j.sbspro.2013.11.090.

29. Walsh, A., \& Resch, R. (2020, August 6). 6 ways the COVID-19 pandemic could change our approach to human capital. Retrieved September 2020, from World Economic Forum: https://www.weforum.org/agenda/2020/08/6-ways-covid-19-will-advance-human-capitalstrategies-and-governance/

30. World Economic Forum. (2020). The Future of Jobs Report 2018. Cologny/Geneva: Centre for the New Economy and Society. Retrieved from World Economic Forum. 